\title{
Midterm results of vascular ring connector in open surgery for aortic dissection
}

\author{
Jeng Wei, MD, MSD, ${ }^{\text {a }}$ Chung-Yi Chang, MD, ${ }^{\text {a }}$ Yi-Cheng Chuang, MD, ${ }^{\text {a }}$ Sung-How Sue, MD, ${ }^{\mathrm{a}}$ \\ Kuo-Chen Lee, MD, ${ }^{a}$ Ching-Wen Wu, MD, ${ }^{b}$ and Cheng-Hsi Chang, $\mathrm{MD}^{\mathrm{b}}$
}

Objectives: This study observed midterm results of vascular ring connectors in surgery for aortic dissection.

\begin{abstract}
Methods: Vascular ring connectors were used as stents in vascular grafts to achieve quick, sutureless anastomoses. Tapes were used to secure ringed vascular grafts from outside the aorta.
\end{abstract}

\begin{abstract}
Results: From November 2007 to February 2011, 113 consecutive patients with aortic dissection, except 3 in preoperative profound shock, underwent open surgery. All underwent aortic reconstruction with vascular grafts and vascular ring connectors: ascending aorta in 29 , descending thoracic aorta in 20 , distal hemiarch plus descending thoracic aorta in 22 , total arch in 14 , ascending aorta plus total arch in 12 , total arch plus descending thoracic aorta in 7, ascending aorta plus arch plus descending thoracic aorta in 8 , and thoracoabdominal aorta in 1. Concomitant operations were 19 Bentall procedures, 14 coronary bypasses, 2 mitral valve replacements, 1 aortic valve replacement, and 1 heart transplant. We used sternotomy to repair $77 \%$ of type B dissections, $83 \%$ with elephant trunks. Time to extubation was $9.0 \pm 6.2$ hours. Average blood loss was $345 \pm 195 \mathrm{~mL}$. Half the patients needed no blood transfusion. In-hospital mortality was $5.3 \%$; late mortality was $2.7 \%$.
\end{abstract}

Conclusions: Use of vascular ring connectors in surgical repair for aortic dissection might reduce risks and improve early and midterm results. With addition of elephant trunk, most type B dissections could be repaired through sternotomy. With the improved surgical results, we can suggest open repair for most uncomplicated type B dissections; however, more long-term follow-up is needed. (J Thorac Cardiovasc Surg 2012;143:72-7)

B Supplemental material is available online.

Open surgical repair for aortic dissection (AD) is challenging. The surgical risks include bleeding from the anastomosis, prolonged cardiopulmonary bypass, and visceral organ ischemia. The wrong surgical approach may further increase the technical difficulties.

To facilitate the surgical anastomosis of fragile aorta and vascular graft, sutureless intraluminal grafts (SILGs) have been used to repair $\mathrm{AD}^{1}$; however, the results have not been promising. ${ }^{2-4}$ Recently, stent-grafts have been introduced to treat type B AD. ${ }^{5-7}$ This technique has not been very reliable, however, and most patients have needed a hybrid approach. ${ }^{8,9}$ We believe that intraluminal grafts

From the Heart Center, ${ }^{\text {a }}$ Cheng-Hsin General Hospital, Taipei, Taiwan; and Tung's Taichung Metro Harbor Hospital, ${ }^{\mathrm{b}}$ Taichung, Taiwan.

Disclosures: J.W. is a consultant for Sunwei Technology Co, Taipei, Taiwan. The authors had full control of the design of the study, the method used, the outcome parameters, analysis of the data, and production of the written report.

Read at the 91st Annual Meeting of The American Association for Thoracic Surgery, Philadelphia, Pennsylvania, May 7-11, 2011.

Received for publication April 9, 2011; revisions received July 29, 2011; accepted for publication Sept 15, 2011; available ahead of print Oct 21, 2011.

Address for reprints: Jeng Wei, MD, MSD, Director of Heart Center, Cheng-Hsin General Hospital, 45 Cheng-Hsin St, Pei-Tou, Taipei, 112, Taiwan (E-mail: jengwei@mac.com).

$0022-5223 / \$ 36.00$

Copyright (c) 2012 by The American Association for Thoracic Surgery doi:10.1016/j.jtcvs.2011.09.013 may reduce bleeding, but the original commercial products were not ideal. We therefore developed a new vascular ring connector (VRC; Vasoring; Sunwei Technology Co, Taipei, Taiwan) to improve the safety of the anastomosis.

The VRC is composed of biocompatible titanium alloy and is made in various sizes (diameter ranging from 12 $\mathrm{mm}$ to $30 \mathrm{~mm}$ ). The device is inserted into either one or both ends of the vascular prosthesis to form a single-ring or double-ring SILG (Figure E1).

Our early results were excellent and have been reported. ${ }^{10}$ We now present our midterm results.

\section{MATERIALS AND METHODS}

After approval was granted by the institutional review boards, we analyzed our patients who underwent open surgery for AD from November 2007 to May 2011. Except for 3 patients who died of preoperative profound shock, 113 consecutive patients ( 81 male and 32 female) underwent open surgery. The average age at operation was $59.1 \pm 11.3$ years (31-79 years), and the mean follow-up was $17.2 \pm 11.6$ months (1-39 months). The ratio of acute to chronic AD was 2.4:1 (80/33). The ratio of type A to type B AD was 1.4:1 (66/47). Six patients had undergone previous operations for AD (Table E1).

The operations were done on an emergency basis in 30 of 113 cases, an urgent basis in 50 of 113, and elective basis in 33 of 113. Preoperatively, 9 had cardiac tamponade and hypotension, 3 had lower limb ischemia, 3 had malperfusion of at least 1 kidney, and 1 had spinal cord ischemia (Table E2)

\section{Preoperative Assessments}

Before surgery, multidimensional computed tomography (MDCT) of the thoracoabdominal aorta and the head and neck arteries were performed. 

Abbreviations and Acronyms
AD $=$ aortic dissection
CCA $=$ common carotid artery
DTA $=$ descending thoracic aorta
IA $=$ innominate artery
$\mathrm{MDCT}=$ multidimensional computed tomography
SCA = subclavian artery
SILG = sutureless intraluminal graft
VRC = vascular ring connector

The locations of entry tear and the blood supply of visceral organs and common femoral artery were assessed. The origin of the right subclavian artery (SCA) was also assessed. Heart MDCT was routinely performed to rule out coronary artery disease.

\section{Surgical Technique of Sternotomy Approach for Entry Tear Located at the Ascending Aorta, Aortic Arch, or Proximal Descending Thoracic Aorta}

Skin preparation included the neck. Arterial pressure catheters were inserted in the bilateral radial arteries. Before heparinization, two 8-mm gelsealed Dacron polyester fabric grafts were individually anastomosed to a single healthy common femoral artery and the right SCA. After sternotomy was performed and the right atrium was cannulated, cardiopulmonary bypass with moderate hypothermia was instituted. The innominate artery (IA), left common carotid artery (CCA), and left SCA were dissected and looped with tapes. Before the aorta was opened, systemic extracorporeal circulation was stopped except for the brain, which was perfused by the right SCA cannula at a flow of 1000 to $1500 \mathrm{~mL} /$ minute. If the ascending aorta was healthy, it was crossclamped, and cardiac arrest was induced by a single dose of histidine-tryptophan-ketoglutarate solution (Custodiol; Essential Pharmaceuticals, LLC, Newtown, Pa) through the aortic root. If the ascending aorta was involved by dissection flap, we would give histidine-tryptophan-ketoglutarate solution through a single-ring SILG that was inserted into the aortic root immediately after the ascending aorta was opened.

According to the locations of entry tear, we treated the patients differently.

Entry tear at the ascending aorta. For entry tear at the ascending aorta (Figure 1), the ascending aorta was replaced with a segment of double-ring SILG. The Bentall procedure might be needed if the tear was close to the aortic valve.

Entry tear at the proximal aortic arch. For entry tear at the proximal aortic arch (Figure 2), the IA, left CCA, and left SCA were ligated at their origins. A double-ring SILG was used to replace the aortic arch. A segment of 6-mm diameter vascular graft was used to create an aorta-left CCA bypass through a separate neck incision. Aorta-IA bypass might be achieved by another graft, either by single-ring SILG or direct carotid anastomosis. Left CCA-left SCA or aorta-left SCA bypass might be performed if the mean pressure of the left radial artery was lower than $60 \mathrm{~mm} \mathrm{Hg}$.

Entry tear at the distal aortic arch. For entry tear at the distal aortic arch (Figure 3), the left CCA and left SCA were ligated at their origins. A double-ring SILG was inserted into the aorta. The proximal VRC was placed between the IA and the left CCA, and the distal VRC was placed below the left SCA. The technique of aorta-left CCA bypass and the criteria for left SCA bypass were the same as for entry tear at the proximal arch.
Entry tear at the proximal descending thoracic aorta. For entry tear at the proximal descending thoracic aorta (DTA; Figure 4), the aortic arch was incised and a single-ring SILG was used as an elephant trunk (10-15 cm long). With the guidewire pulling technique (described further later in this text), the free end of the SILG was brought into the DTA and the VRC was fixed at the level just below the left SCA.

Entry-tear at the proximal DTA with retrograde dissection to the ascending aorta. As with entry tear at the proximal arch, for entry tear at the proximal DTA with retrograde dissection to the ascending aorta, the whole segment of ascending aorta and aortic arch was replaced with a double-ring SILG. An extra length of graft was used as an elephant trunk to cover the entry tear at the proximal DTA.

Guidewire pulling technique. While the aorta was open, a guidewire was inserted into the femoral artery through the graft used for cardiopulmonary bypass. The tip of the guidewire was moved forward and upward until it came out from the true lumen of the aortotomy. A knot was made on the guidewire, and the free end of the elephant trunk was fixed to the knot with a stitch that was further snared by a plastic tube. By pulling the guidewire, the free end of the elephant trunk could be easily placed in the true lumen of the DTA. The snare was released, and the guidewire was removed from the aortotomy.

\section{Surgical Technique of Thoracotomy Approach for Entry Tear Located at the Middle or Lower Portion of the DTA}

In the thoracotomy approach for entry tear located at the middle or lower portion of the DTA (Figure 5), a left posterolateral thoracotomy incision was made through the 4 th or 5 th intercostal space. Cardiopulmonary bypass was then instituted through the left femoral artery and vein. After proximal and distal control was achieved, the aorta was incised and a double-ring SILG was inserted into the aorta and fixed with tapes.

\section{Postoperative Follow-up}

All patients underwent intraoperative transesophageal echocardiographic studies before and immediately after the repair. MDCT studies were carried out before discharge and then 3 to 6 months later.

\section{RESULTS \\ General}

All patients with type $\mathrm{A} A D$ and $77 \%$ of those with type B AD (36/47) underwent median sternotomy. Elephant trunks were used in $83 \%$ of the type B AD repairs (30/ 36 ) and $6 \%$ of the type A AD repairs (4/66). For type A $\mathrm{AD}$ repairs, the cardiac ischemic time was $144 \pm 95$ minutes, the pumping time was $215 \pm 78$ minutes, the anastomotic time for VRC was $3.5 \pm 4.5$ minutes, and the operative time was $6.5 \pm 3.1$ hours. Average hospital stay was $14 \pm 10$ days. For type B AD repairs, the cardiac ischemic time was $54 \pm 65$ minutes, the pumping time was $110 \pm$ 56 minutes, the anastomotic time of VRC was $3.1 \pm 2.3$ minutes, and the operative time was $5.4 \pm 3.2$ hours. Average hospital stay was $14 \pm 8$ days (Table E3).

All patients underwent aortic reconstruction with vascular grafts and VRCs: ascending aorta in 29, DTA in 20, distal hemiarch plus DTA in 22, total arch in 14, ascending aorta plus total arch in 12, total arch plus DTA in 7, combined ascending aorta plus arch plus DTA in 8, and thoracoabdominal aorta in 1 (Table E4). Concomitant 


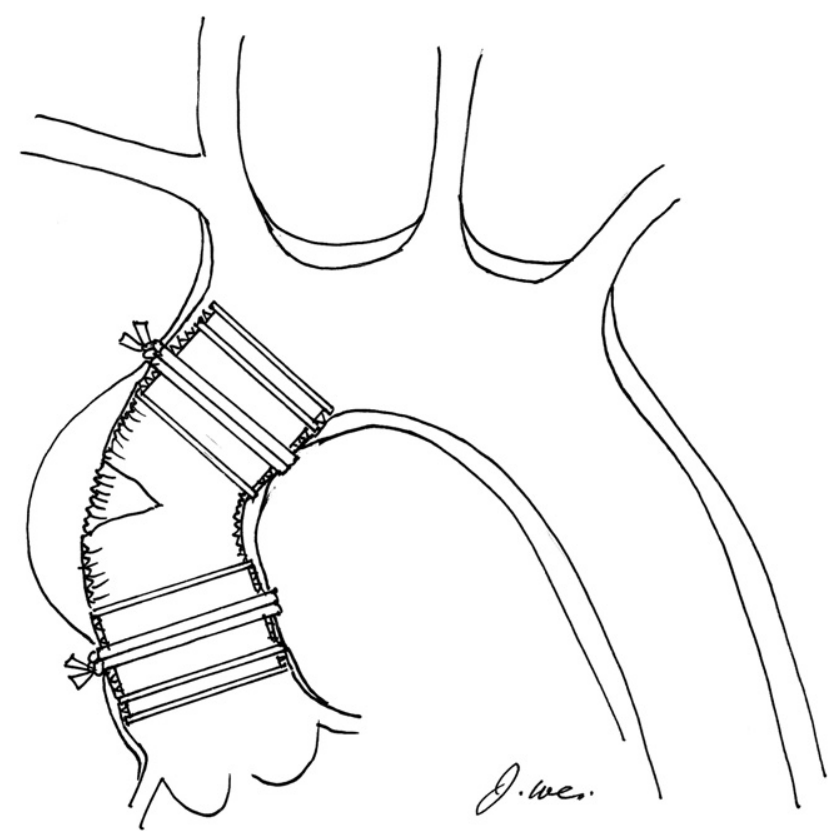

FIGURE 1. Surgical diagram showing the technique of repair of entry tear located at ascending aorta.

operations included 19 Bentall procedures, 14 coronary artery bypass grafting procedures, 2 mitral valve replacements, 1 aortic valve replacement, and 1 heart transplant (Table E5).

Excepting the 6 patients who died, all of whom had prolonged mechanical ventilation, time to extubation was $9.0 \pm 6.2$ hours. Average blood loss was $345 \pm 195$ $\mathrm{mL}$. Average amount of blood transfused was $268 \pm$ $163 \mathrm{~mL}$, with 57 of 113 patients $(50.4 \%)$ receiving no blood transfusion. None had dislodgment of the ring from the anastomotic site either during or after the operation (Table E6).

The patient who underwent concomitant heart transplant was operated on for a recurrent arch $\mathrm{AD}$ and dehiscence of the aortic conduit from the aortic root after a previous Bentall operation performed for AD. This woman with Marfan syndrome was considered to have an inoperable condition unless repair could be combined with heart transplant. She underwent combined heart transplant and total replacement of the ascending aortic, arch, and DTA. This patient was still very well 2 years after the surgery.

\section{Surgical Complications and In-Hospital Mortality}

Six patients died of various complications: cerebral air embolism in 1 case (type B), spinal cord ischemia in 1 case (type B), bleeding in 2 cases (both type A), and ischemic bowel in 2 cases (both type A; Table E7). Two patients with type $\mathrm{A} A \mathrm{AD}$ had transient cerebellar ischemia; however, both recovered well. Two patients with type B AD had transient recurrent laryngeal nerve palsy. Two patients with type

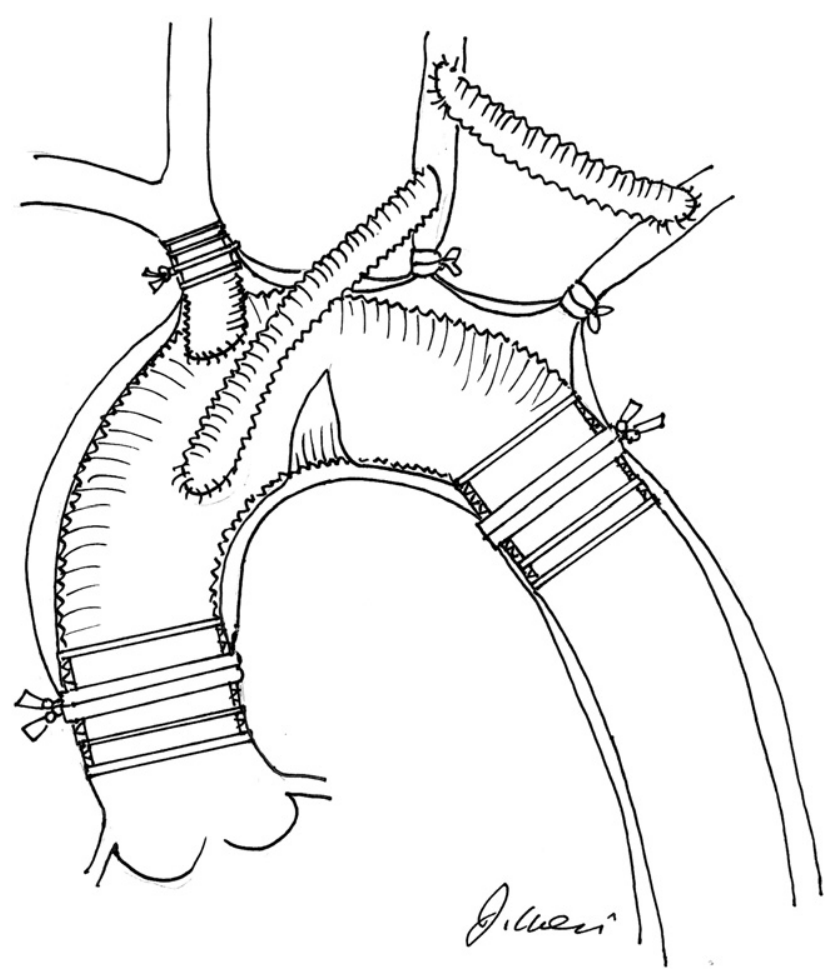

FIGURE 2. Surgical diagram showing the technique of repair of entry tear located at the proximal aortic arch.

A AD had renal failure and received temporary hemodialysis. No one had bleeding from the VRC anastomotic sites. The overall in-hospital mortality was 6 of 113 patients $(5.3 \%)$.

\section{Late Outcomes}

Three of 113 patients $(2.7 \%)$ died after discharge (Table E8). Two patients with type A AD died of cerebral hemorrhage, probably as a result of poor control of blood pressure. One patient with type $\mathrm{B} A D$ died of upper gastrointestinal bleeding. One patient with type B AD had thrombosis of the lower abdominal aorta develop; this was successfully treated with axillofemoral bypass. One patient with type B AD had a minor stroke at home but recovered well. One patient with type A AD had thrombosis of the left CCA develop; this was successfully treated with carotid-carotid bypass. None of the patients had recurrent AD.

False aneurysm formation or hemolysis. No one had a false aneurysm develop at the site of anastomosis as result of migration of the VRC. No patients had evidence of hemolysis.

Outcomes of false lumen in patients with elephant trunk. Immediate closure of the false lumen was observed by transesophageal echocardiographic studies in all but 1 patient. MDCT studies performed at the outpatient department showed the same results. 


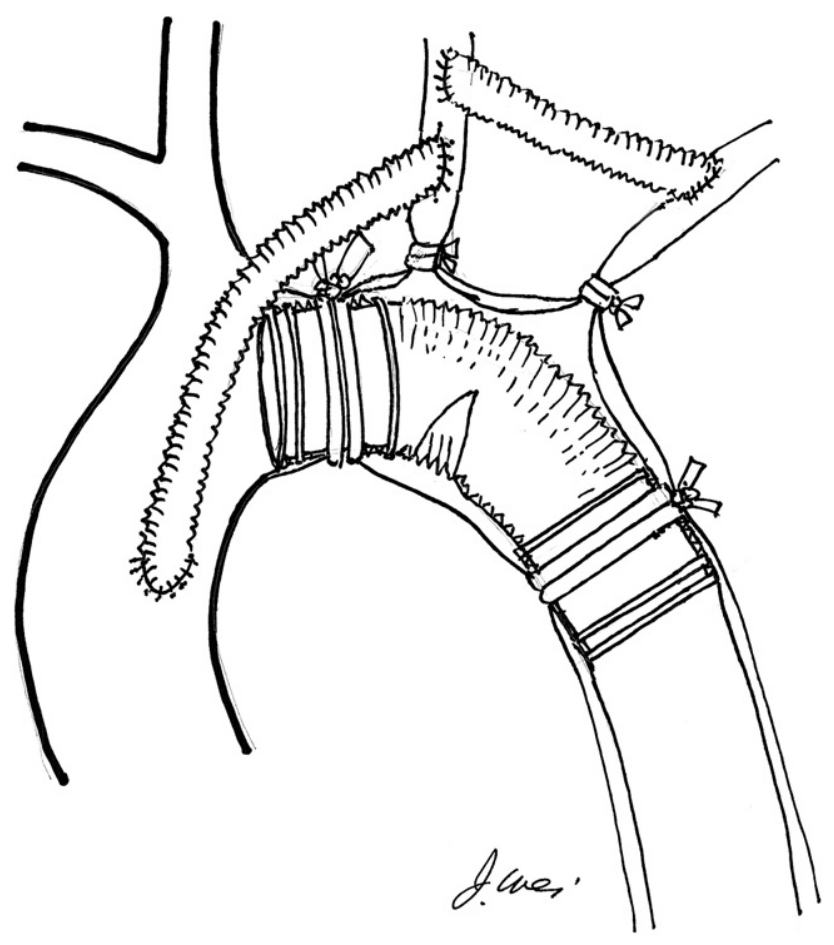

FIGURE 3. Surgical diagram showing the technique of repair of entry tear located at the distal aortic arch.

Major cardiac events. There were no cardiac events during the period of follow-up, even among those who underwent combined heart operations.

Need for reoperation. No patients required reoperation during this follow-up period.

\section{DISCUSSION}

\section{Bleeding Risks}

Replacement of a segment of dissected aorta with a vascular prosthesis with sutures is not only time-consuming but also difficult, because the tissue is very fragile. Lethal bleeding from the suture holes is common, because the fine threads may cut through the aortic wall. Theoretically, the holding power of an anastomosis depends on the area of contact surface. The tapes used in fixation for intraluminal grafts provide much bigger contact area than do stitches. We could hardly see any bleeding from the VRC anastomotic sites. Meanwhile, bleeding related to the coagulopathy was also decreased as a result of shortened extracorporeal circulation time. This reduction in bleeding may explain why half of our patients needed no blood transfusions either during or after surgery.

\section{Organ Ischemia}

Brain circulation was maintained with right SCA perfusion during circulatory arrest. None of the patients had cerebral ischemia.

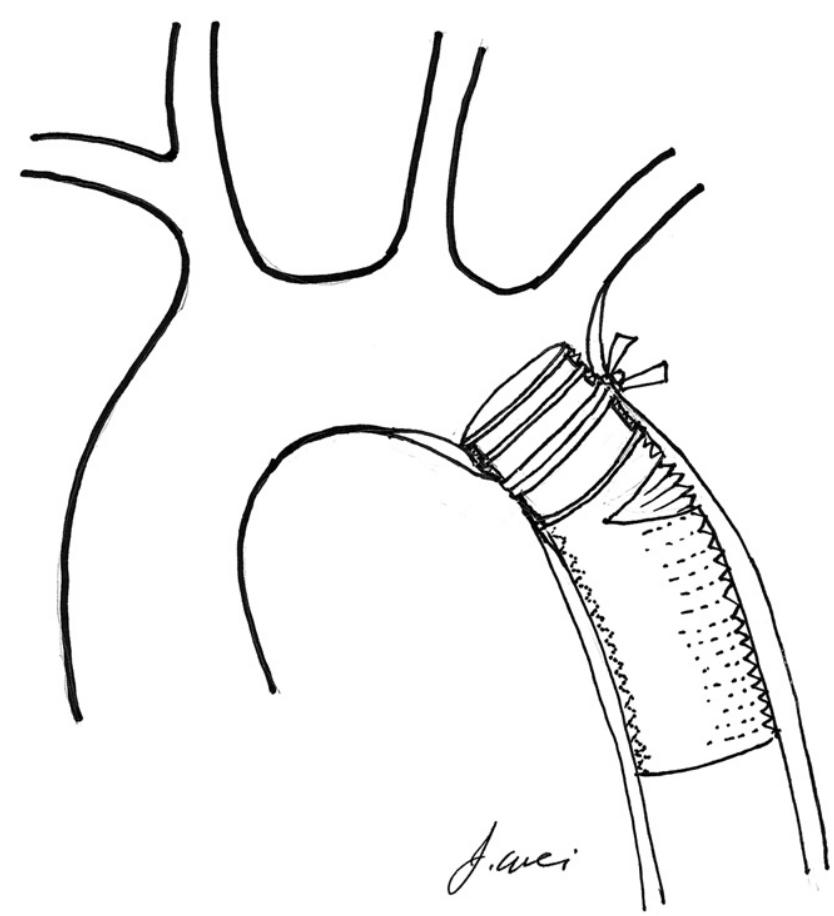

FIGURE 4. Surgical diagram showing the technique of repair of entry tear located at the proximal descending thoracic aorta.

We ligated the left SCA without aorta-left SCA bypass in most cases of arch replacement. Two of the patients who underwent arch replacement had transient cerebellar ischemia. We therefore may have to change our policy in the future.

One patient had spinal cord ischemia after the surgery and eventually died. Eight other patients who underwent nearly total replacement of the DTA, however, did not have spinal cord ischemia.

Ischemic bowel is a critical complication: 2 of the 3 affected patients in our series died. Preoperative MDCT studies can provide important information on the anatomy of the dissection flap in the abdominal aorta. During circulatory arrest, intermittent perfusion of the abdominal visceral organs through the femoral cannula is also recommended.

\section{Surgical Approach}

The wrong approach may result in poor exposure and mortality. It is obvious that most patients with type $\mathrm{A} \mathrm{AD}$ with entry tear at the ascending aorta or arch should undergo sternotomy. The surgical approach for patients with entry tear located at the distal arch or proximal DTA, however, might be more difficult to determine. With the use of VRC and elephant trunk procedures, almost all these patients could easily be operated on through a sternotomy. Only in cases of entry tears located at the middle or lower DTA do we use thoracotomy. 


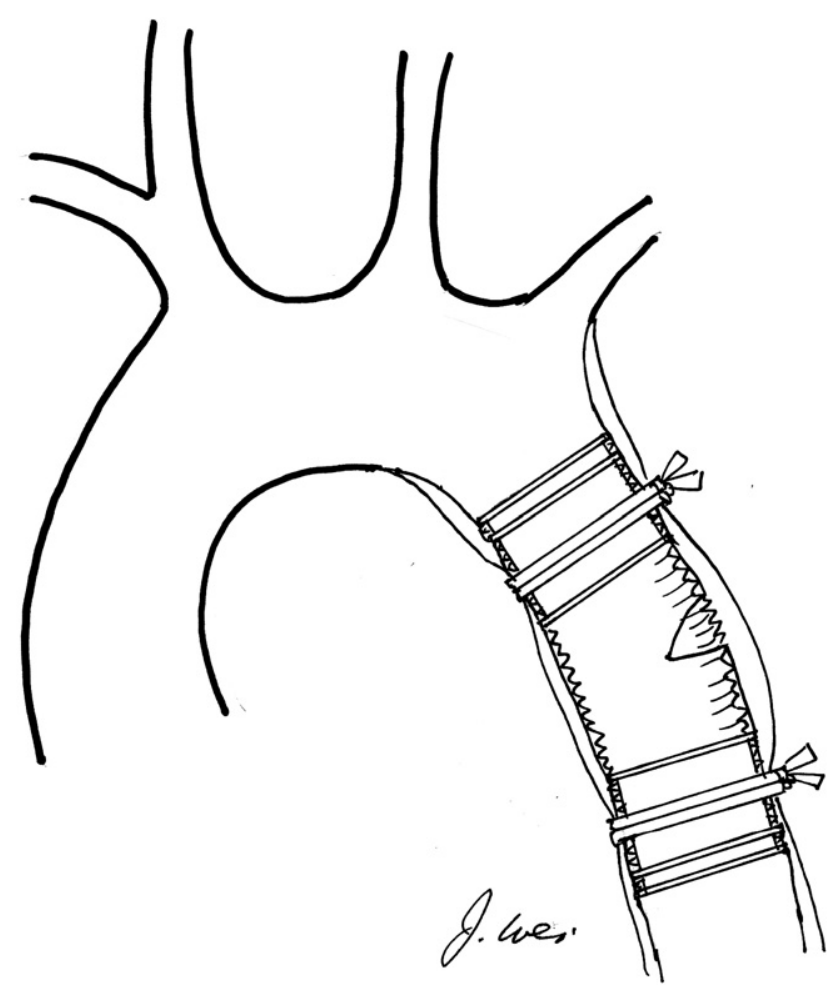

FIGURE 5. Surgical diagram showing the technique of repair of entry tear located at the middle or lower portion of the descending thoracic aorta.

\section{Elephant Trunk}

The advantages of the elephant trunk procedure have been stressed by Svensson and colleagues ${ }^{11}$ and confirmed by others. ${ }^{12}$ We also found that the combined use of VRC and elephant trunk procedures might make the repair of the proximal portion of the DTA easier. The intraoperative transesophageal echocardiography revealed that the false lumens in all except 1 patient were closed immediately after the procedure. The sole exception was probably due to the inadequate length of the elephant trunk $(7 \mathrm{~cm})$.

The use of the guidewire pulling technique to insert an elephant trunk was simple. During circulatory arrest, we found that the true lumen of the aorta was usually wide open, and the guidewire would always pass through the true lumen.

\section{Total Arch Replacement}

The technique of island flap may not be useful for patients with $\mathrm{AD}$, because the dissection flap might extend to the arch vessels. We suggest performing aorta-carotid bypass grafting through separate neck incisions. In our series, 1 patient underwent intraluminal grafting for aortaleft CCA bypass and had left CCA thrombosis develop. Since then, we have routinely used suture techniques for aorta-left CCA bypass.

Because of the simplicity of aorta-carotid bypass through separate neck incisions, we recommend replacing the total arch whenever this seems inevitable.

\section{Nearly Total Replacement of Thoracic Aorta}

In certain circumstances, we needed to replace the middle or lower portion of the DTA through a sternotomy in patients with type A AD. For example, a patient with a long entry tear at the DTA may also have a retrograde dissection flap extending to the arch and ascending aorta. In this circumstance, the entire thoracic aorta, including the ascending aorta, arch, and DTA, must be replaced. This is technically feasible if we use the intraluminal graft. While the heart apex is lifted, the left pleura is opened, and dissection can be performed to free the lower DTA, which is looped with tapes. A Coda balloon catheter (Cook Medical Inc, Bloomington, Ind) can then be used to pull the distal VRC to the lower DTA for fixation. The lowest portion of the DTA should be spared to prevent spinal cord injury because of the higher incidence of origin of the Adamkiewicz artery from this part of the aorta.

\section{Recurrent AD}

Complete repair of the diseased aorta is the goal of surgery for $\mathrm{AD}$. Incomplete repair results in residual $\mathrm{AD}$, which in turn may lead to late death. Five of our patients were referred from other hospitals for reoperation because of incomplete repair during the first operations. With the use of the VRC, none had recurrent AD during this follow-up period.

\section{Pseudoaneurysm and Hemolysis Associated With Intraluminal Grafts}

The early results of the use of ringed SILGs in repairing the $\mathrm{AD}$ were satisfactory. ${ }^{1,13,14}$ Unfortunately, ringed SILGs were abandoned in response to late reports of pseudoaneurysm formation, which was considered to be caused by the migration of the ring. ${ }^{2,3}$ The Meadox intraluminal graft (Meadox Medical, Oakland, NJ) was the commercial product used in many countries; however, the lack of a furrow on the surface of the plastic ring may have been a cause of migration (Figure E2). Bernardes and associates ${ }^{15}$ used a different ring that had a $2.5-\mathrm{mm}$ deep groove for fixation and was placed outside the vascular graft. Their clinical report of this graft in the treatment of $\mathrm{AD}$ was excellent. Hemolytic anemia related to the use of intraluminal graft was reported by Sayar and colleagues ${ }^{4}$; however, our patients had no such complications.

\section{Stent-Graft}

Stent-grafts have been used to treat AD since 1999..$^{5-7}$ The advantages of stent-grafts are obvious; however, they are still limited by the landing zones and the risks of new entry. ${ }^{8}$ Most patients still need hybrid surgery. ${ }^{9}$ The use of VRC does not exclude the use of stent-grafts in the treatments of AD. The more tools we have, the better care we can provide for our patients with $\mathrm{AD}$. 


\section{Policy of Surgical Treatment for Type B AD}

According to a cohort study done by the International Registry of Aortic Dissection, the in-hospital mortality after surgical treatment of type B AD was higher than with medical therapy (32\% vs $10 \%) .{ }^{16}$ Even in uncomplicated type $\mathrm{B} \mathrm{AD}$, however, the risk of AD-related events is much higher for those who have patent false lumen or a maximal aortic diameter greater than $40 \mathrm{~mm} .{ }^{17}$ Our in-hospital mortality for patients with type B AD was 2 of 42 patients $(4.3 \%)$, and we believe that the risk will be even lower after accumulation of experience. We might therefore suggest operating on patients with uncomplicated type $\mathrm{B} A D$ if the false lumen is still patent; however, a greater number of longer-term follow-up studies of cases are needed before we can reach a definitive conclusion.

\section{CONCLUSIONS}

First, the use of VRC in surgical repair for AD may reduce the risks and improve the early and midterm results. Second, with VRC and elephant trunk, most type B ADs can be repaired through median sternotomy. Finally, in light of the improved surgical results, we suggest treating type B $\mathrm{AD}$ more aggressively if the false lumen is still open; however, more and longer-term follow-up is needed before we can make a definitive conclusion.

We thank Joseph J Chang, PhD, for his continuous help in technical advice and experimental design of the vascular ring connector.

\section{References}

1. Liu DW, Lin PJ, Chang CH. Treatment of acute type A aortic dissection with intraluminal sutureless prosthesis. Ann Thorac Surg. 1994;57:987-91.

2. West D, Scott DH, Walker WS. Complete aortic dehiscence as a late complication of an aortic sutureless graft. Eur J Cardiothoracic Surg. 2008;34:451.

3. Chang JP, Lu HI, Hsieh MJ, Kao CL, Wu CJ. Pseudoaneurysm formation 12 years after ringed intraluminal graft replacement for type B aortic dissection. Chang Gung Med J. 2004;27:614-7.

4. Sayar H, Dietl CA, Helms A, Rabinowitz I. Fragmentation hemolytic anemia 8 years after replacement of ascending aorta with a sutureless intraluminal graft. Am J Hematol. 2006;81:175-7.

5. Dake MD, Kato N, Mitchell RS, Semba CP, Razavi MK, Shimono T, et al. Endovascular stent-graft placement for the treatment of acute aortic dissection. $N$ Engl J Med. 1999;340:1546-52.

6. Nienaber CA, Fattori R, Lund G, Dieckmann C, Wolf W, von Kodolitsch Y, et al. Nonsurgical reconstruction of thoracic aortic dissection by stent-graft placement. N Engl J Med. 1999;340:1539-45.

7. Parsa CJ, Williams JB, Bhattacharya SD, Wolfe WG, Daneshmand MA, McCann RL, et al. Midterm results with thoracic endovascular aortic repair for chronic type B aortic dissection with associated aneurysm. J Thorac Cardiovasc Surg. 2011;141:322-7.

8. Dong ZH, Fu WG, Wang YQ, Wang CS, Yan ZP, Guo DQ, Xu X, Chen B. Stent graft-induced new entry after endovascular repair for Stanford type B aortic dissection. J Vasc Surg. 2010;52:1450-8.

9. Chen LW, Dai XF, Zhang GC, Lu L. Total aortic arch reconstruction with open placement of triple-branched stent graft for acute type A dissection. $J$ Thorac Cardiovasc Surg. 2010;139:1654-5.e1.

10. Wei J, Chang CY, Chuang YC, Sue SH, Lee KC, Tung D. A new vascular ring connector in surgery for aortic dissection. J Thorac Cardiovasc Surg. 2009; 138:674-7.

11. Svensson LG, Kim KH, Blackstone EH, Alster JM, McCarthy PM Greenberg RK, et al. Elephant trunk procedure: newer indications and uses. Ann Thorac Surg. 2004;78:109-16.

12. Suhdo Y, Taniquchi K, Matsue H, Takahashi T, Toda K, Hata H, et al. Successful total arch replacement with long elephant trunk for chronic aortic dissection (DeBakey IIIb). Ann Thorac Surg. 2007;84:659-61.

13. Dureau G, Villard J, Geroge M, Deliry P, Froment JC, Clermont A. New surgical technique for the operative management of acute dissections of the ascending aorta. Report of two cases. J Thorac Cardiovasc Surg. 1978;76:385-9.

14. Ablasa SG, Ghosh SC, Grana VP. Use of a ringed intraluminal graft in the surgical treatment of dissecting aneurysms of the aorta: A new technique. $J$ Thorac Cardiovasc Surg. 1978;76:390-6.

15. Bernardes RC, Reis FA, Lima LC, Monteiro EL. Onze anos de experiencia com o emprego do anel intraluminal para o tratamento das doencas da aorta. Rev Bras Cir Cardiovasc. 1999;14:200-6. Portuguese.

16. Suzuki T, Mehta RH, Ince H, Nagai R, Sakomura Y, Weber F, et al. Clinical profiles and outcomes of acute type B aortic dissection in the current era: lessons from the International Registry of Aortic Dissection (IRAD). Circulation. 2003;108 Suppl. 1:II312-7.

17. Onitsuka S, Akashi H, Tayama K, Okazaki T, Ishihara K, Hiromatsu S, et al. Long-term outcome and prognostic predictors of medically treated acute type B aortic dissections. Ann Thorac Surg. 2004;78:1268-73.

\section{Discussion}

Dr W. Randolph Chitwood, Jr (Greenville, NC). How do you think this is going to compare with stent-grafting? This technique seems to be an old innovation. Gerald Lemole developed a "tie-in" prosthesis many years ago. Actually, around the early part of the last century, Payr used vitallium tubes to perform sutureless end-to-end-anastomoses. So it is an old technique that you have revised. How is your method going to compare with stent-grafting?

Dr Wei. Well, there are still a lot of problems with the stentgraft used for $\mathrm{AD}$, for example in the newly formed dissection because the intima is so fragile. Maybe in the future the stent-graft will be improved; at present however, I still believe that open surgery like this is the treatment of choice for most of my patients.

Dr Chitwood. You have certainly shown very good results with this method. Did your group experience any paraplegia?

Dr Wei. Only 1 case. 


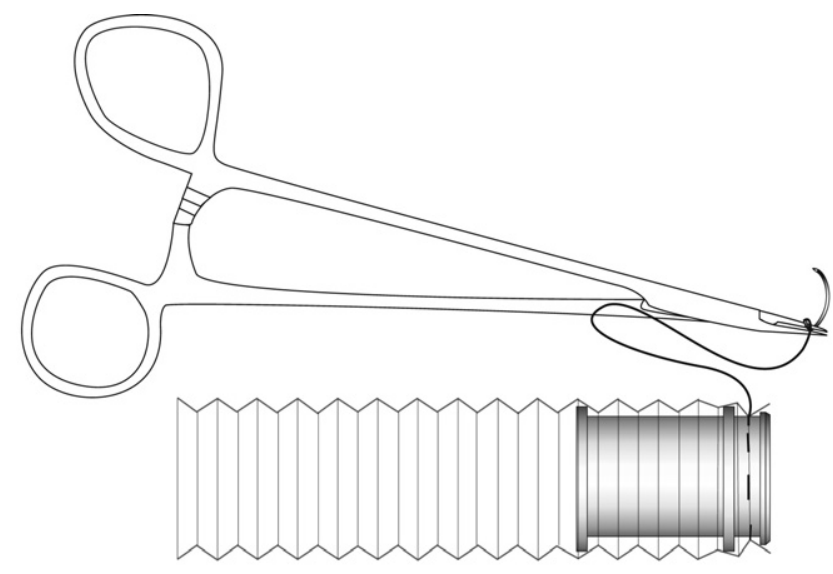

A

GRAFT

VRC

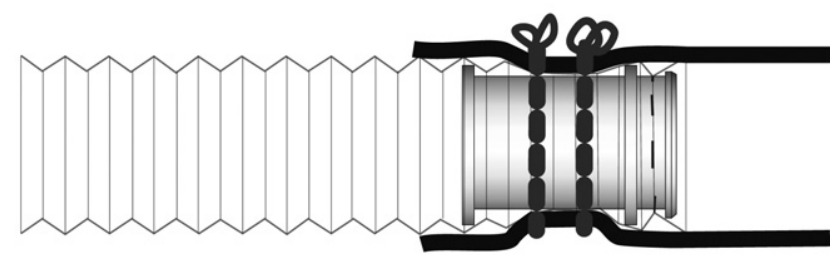

B GRAFT

VRC

AORTA

FIGURE E1. Vascular ring connector $(V R C)$ and the formation of intraluminal graft: There are 2 grooves on the outer surface of the vascular ring connector: the narrow groove is used for suture fixation between the vascular ring connector and the vascular prosthesis, and the wider groove is used for fixation between the vascular ring connector and the aorta (A). Braided tapes are used to tie around the overlapping region of the aorta and the vascular ring connector to form a suture-less anastomosis (B).
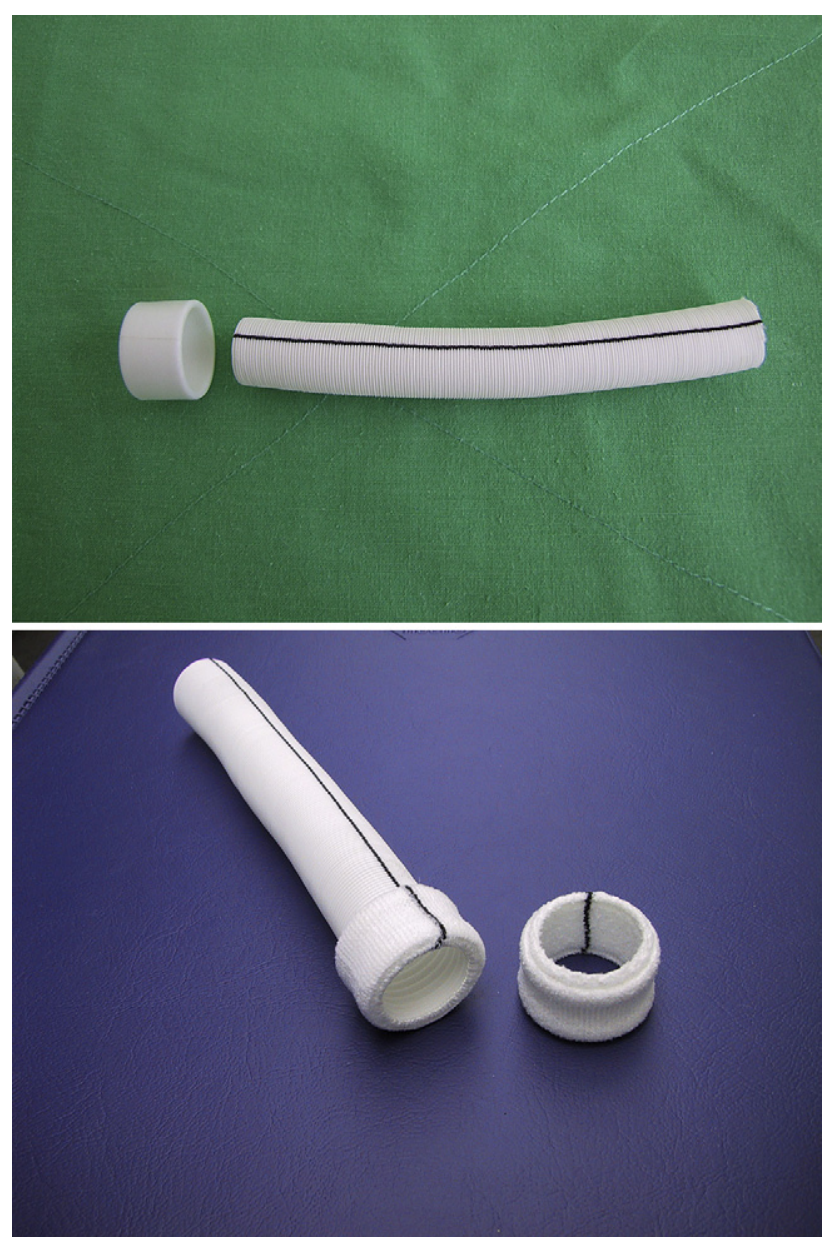

FIGURE E2. The ring of the Meadox intraluminal graft (Meadox Medical, Oakland, NJ). After removal of the cover, there is no furrow on the surface of the plastic ring. 
TABLE E1. Demographics

Male/female ratio

Age (y)

Mean \pm SD

Range

Acute/chronic ratio

Type A/type $\mathrm{B}$ ratio

Traumatic (no.)

Reoperative surgery for dissection (no.)

Sternotomy approach (no.)

Elephant trunk (no.)

Total cases (no.)
TABLE E3. General surgical results

Sternotomy approach (no.)

$102 / 113(90.3 \%)$

Sternotomy in type B (no.)

$36 / 47(77 \%)$

$59.1 \pm 11.3$

31-79

$80: 33$

$66: 47$

6

6

$102 / 113(90.3 \%)$

33

113

Elephant trunk (no.)

In type B (sternotomy)

$30 / 36(83 \%)$

In type $\mathrm{A}$

$4 / 66(6 \%)$

Cardiac ischemic time (min, mean $\pm \mathrm{SD}$ )

Type A

$144 \pm 95$

Type B

$54 \pm 65$

Pumping time (min, mean \pm SD)

Type A

$215 \pm 78$

Type B

$110 \pm 56$

Anastomotic time for vascular ring connector (min, mean $\pm \mathrm{SD}$ )

Type A

$3.5 \pm 4.5$

Type B

$3.1 \pm 2.3$

Hospital stay (d, mean $\pm \mathrm{SD})$

$14 \pm 8$

TABLE E4. Segments of aortic replacement

\section{TABLE E2. Preoperative comorbidities}

Emergency operations

Urgent operations

Elective operations

Cardiac tamponade and hypotension

Malperfusion of lower limbs

Malperfusion of kidney

Spinal cord ischemia

\begin{tabular}{lr}
\hline & No. \\
\hline Ascending aorta & 29 \\
Descending thoracic aorta & 20 \\
Distal hemiarch plus descending thoracic aorta & 22 \\
Total aortic arch & 14 \\
Ascending aorta plus total aortic arch & 12 \\
Total aortic arch plus proximal third descending thoracic aorta & 7 \\
Ascending aorta plus total aortic arch plus proximal 3 quarters of & 8 \\
$\quad$ descending thoracic aorta & 1 \\
Thoracoabdominal aorta & 113 \\
Total & \\
\hline
\end{tabular}


TABLE E5. Concomitant procedures

\begin{tabular}{lr}
\hline & No. \\
\hline Bentall operation & 19 \\
Coronary artery bypass grafting & 14 \\
Mitral valve replacement & 2 \\
Aortic valve replacement & 1 \\
Heart transplant & 1 \\
Total & 37 \\
\hline
\end{tabular}

TABLE E7. Surgical complications and in-hospital mortality

\begin{tabular}{lll}
\hline \multicolumn{1}{c}{ Complication } & \multicolumn{1}{c}{ No. and type } & \multicolumn{1}{c}{ Results } \\
\hline Cerebral air embolism & 1 type B & Died \\
Spinal cord ischemia & 1 type B & Died \\
Bleeding & 2 type A & Died \\
Ischemic bowel & 3 type A & 2 died, 1 survived after \\
& & bowel resection \\
Cerebellar ischemia & 2 type A & Recovered \\
Recurrent laryngeal & 2 type B & Recovered \\
$\quad$ nerve palsy & & \\
Renal failure & 2 type A & Recovered \\
Mortality & 4 type A, 2 type B & $6 / 113(5.3 \%)$ \\
\hline
\end{tabular}

TABLE E6. Other early results

Time to extubation $(\mathrm{h}$, mean $\pm \mathrm{SD})$

Average blood loss (mL, mean $\pm \mathrm{SD}$ )

Average amount of blood transfusion

$(\mathrm{mL}$, mean $\pm \mathrm{SD})$

No blood transfusion (no.)

Dislodgement of vascular ring connector during

or after operations (no.)
$9.0 \pm 6.2$

$345 \pm 195$

$268 \pm 163$

$57 / 113(50.4 \%)$

$0 / 113$
TABLE E8. Late outcomes

\begin{tabular}{lcll}
\hline \multicolumn{1}{c}{ Complications } & No. and type & \multicolumn{1}{c}{ Treatments } & Results \\
\hline $\begin{array}{l}\text { Intracranial } \\
\text { hemorrhage }\end{array}$ & 2 type A & Conservative & Died \\
$\begin{array}{c}\text { Gastrointestinal } \\
\text { bleeding }\end{array}$ & 1 type B & Conservative & Died \\
Distal thrombosis & 1 type B & $\begin{array}{c}\text { Axillofemoral } \\
\text { bypass }\end{array}$ & Recovered \\
Cerebral embolism & 1 type A & $\begin{array}{c}\text { Conservative } \\
\text { Carotid-carotid } \\
\text { bypass }\end{array}$ & Recovered \\
Carotid artery & 1 type A & \\
$\quad$ thrombosis & & & \\
Recurrent dissection & 0 & & \\
False aneurysm & 0 & & $3 / 13(2.7 \%)$ \\
$\quad$ formation & & & \\
Major cardiac events & 0 & & \\
Need for reoperation & 0 & & \\
Late mortality & 2 type A, \\
& 1 type B & & \\
\hline
\end{tabular}

